\title{
Electrical Bus Performance Modeling for Urban Environments
}

\author{
Deborah Perrotta \\ MIT-Portugal \\ Alexandre Teixeira, Helena Silva and Bernardo Ribeiro
CEIIA
}

Joao Afonso

University of Minho

\begin{abstract}
Electric vehicles are seen as a key driver to address the issue of global warming, mainly through their zero tailpipe emissions operation and energy efficiency improvements. However, this does not solve the problem of urban chaos, related to traffic congestion and parking space cluttering, which contribute to increase human stress and overall economic productivity decrease. To address all these issues, electric urban buses come as an obvious solution, and they also have the advantages of being quieter than regular buses and of promoting a better travel experience to passengers.

Nowadays there are already electric buses operating in some parts of the world and one of the main concerns is their high weight, which is mainly due to the amount of batteries they carry in order to have an adequate range. Several strategies are possible and are being tested to provide buses with adequate operability in terms of range: battery swapping at central stations, battery charging at central stations on slow or fast charge rates and sizing the battery pack to the route of the electric bus using fast charge on bus stops.

This paper intends to provide a mathematical model for the electric bus powertrain and its routes, based on a created driving cycle that simulates an acceleration and deceleration period between two stops of a bus. The main objective is to verify how much of the energy recovered from regenerative braking can be absorbed by lithium-ion batteries and to verify whether the supercapacitors can excel the batteries for this purpose. The intent is to reduce the amount of batteries carried, in the attempt to increase the bus efficiency by optimizing regenerative braking capabilities and possibly reduce overall system weight.
\end{abstract}

CITATION: Perrotta, D., Teixeira, A., Silva, H., Ribeiro, B. et al., "Electrical Bus Performance Modeling for Urban Environments," SAE Int. J. Alt. Power. 1(1):2012, doi:10.4271/2012-01-0200.

\section{INTRODUCTION}

Urban and suburban centers rely upon their transportation infrastructure for the well-being of their population, assuring their mobility. This mobility can be directly related to a sustainable urban development, due to the economic, social and environmental impacts that it has over the population. [1].

Many analyses on the social, economic and environmental costs and impacts of urban expansion have concentrated on the "invasive" nature of the automobile, consequence of their high flexibility on providing access to the increasingly dispersed urban functions. There is a persuasive picture in the urban lifestyle mindset in which the car is an essential element, thus contributing towards increase of traffic congestion and mobility reduction [2]. These factors lead to an increasingly high amount of circulating cars, as expressed in Figure 1 for the European Union, which is detrimental to a sustainable urban development.

Based on what was presented, public transportation represents a solution for both a sustainable urban development and a reduction of traffic congestion, as it means a decrease on the number of circulating cars, once those people change of attitude will make them leave their cars at home. This change of attitude is somehow expected. People are becoming more environmentally aware and providing a clean mean of public transportation will persuade people to use it more often and thus contributing to an overall traffic reduction and consequently to a cleaner environment within cities and an overall energy consumption reduction. 


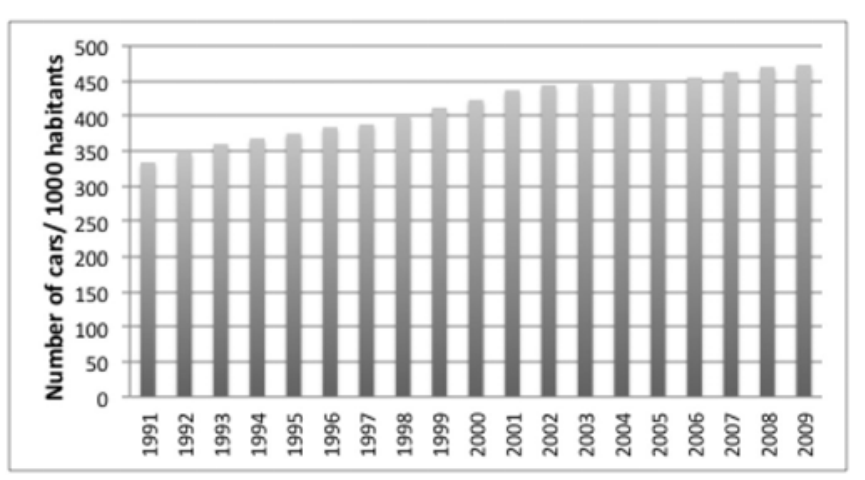

Figure 1. Number of cars per thousand habitants along time for the European Union Source: Eurostat [3]

Another well-known disadvantage associated with the large spread of automobiles relates with Green House Gas (GHG) emissions. According to NASA, motor vehicles are the largest net contributor to global warming pollution, followed by the burning of household biofuels (i.e. wood and animal dung) and raising livestock [4]]. Besides, GHG emissions have negative effects on the earth's ecosystems as a whole, studies prove that by reducing the air pollution (namely fine-particulate) in $10 \mu \mathrm{g}$ per cubic meter, an overall increase in life expectancy of $15 \%$ is observed [ 5 ].

In this sense, sole incentives and investment on conventional city buses - equipped with internal combustion engine - do not seem an adequate attempt towards solving all previous issues. On the other hand, electric buses emerge as a more comprehensive solution to solve both the air pollution issue - due to the absence of tailpipe emissions - as well as the "urban chaos" problem.

Electric buses also have a plenty of other positive aspects. The electric engine causes far less vibration throughout the vehicle, making for a more comfortable journey for those on board without the 'rattling' often experienced when a bus is at lights or a stop. A reduction in vibration also increases the life and reduces maintenance requirements of the bus, making it a cost-effective option for operators [ 6$]$.

Another quality associated with electric buses is their reduced noise. They are noticeably quiet, lowering noise pollution and increasing comfort for those onboard. Although the initial introduction of an electric transport system and fleet can be costly, as a long-term mode of public transport they are surprisingly cost-effective in terms of lifespan and upkeep [].

Nowadays there are already some electric buses in operation around the world. The Portuguese company CaetanoBus has launched its electric bus powered by lithiumion batteries in 2011 for a 3-month test phase in Portugal. This company will also supply one of these models for Offenbach, a German city where it will operate under regular service. Moreover, Sinautec Automobile Technologies [7], and its Chinese partner, Shanghai Aowei Technology Development Company, have spent the past three years demonstrating their supercapacitor bus model in China without any incident or failure. Another company that has developed its own electric bus using lithium-titanate Altairnano [] batteries is Proterra [9]], which launched its newest model EcoRide BE35 ${ }^{\mathrm{TM}}$ at California in 2010 for a testing phase.

In a general way, one of the main concerns regarding electric buses is their weight, which is significant due to the amount of batteries they have to carry in order to have an equivalent operational range as regular internal combustion engine buses. It is also important to mention that batteries represent the highest investment when considering the whole electric bus. Therefore, the main challenge for electric buses is to increase their efficiency and reduce costs. Reducing the battery size and weight is a natural strategy to be followed. One of the ways to do that is by implementing the use of supercapacitors, which has a much higher power density quick storage and release of energy [10]- and thus are capable of absorbing a higher amount of the regenerative braking energy, which is generated at a rate (power) level that is not supported by conventional batteries [11]. This advantage could also be used for the acceleration of the vehicle which is worthy analyzing. The direct impact of implementing supercapacitors would be the possible reduction of the weight of the bus as the battery pack can be reduced. At the same time battery life is enlarged due to the reduction of energy transfer rate from and to the battery, since the energy for acceleration and from regenerative braking is transferred mainly between the super-capacitors and the motor [11].

In order to better study the possibility of reducing the battery pack, a mathematical model was developed to simulate the behavior of an electric bus on an urban environment, namely on a driving cycle representing the distance between two bus stops. The main idea is to investigate the amount of required energy to complete this cycle and the amount that can be recovered by the regenerative braking. With these results, the possibility of replacing part of the battery pack by a supercapacitors bank is approached.

\section{SYSTEM MODELING STRUCTURE}

A mathematical model of the electric bus performance was implemented in MATLAB Simulink. This model has several subsystems, which are used to calculate specific parameters. One of these subsystems represents the vehicle powertrain, taking into account the forces that work against its movement and the gear ratios involved. An output of this subsystem computes the amount of required energy for a driving cycle to be completed. There is a third subsystem that calculates the amount of energy that may be possibly recovered from the regenerative braking, taking into account the kinetic energy of the vehicle. The two other subsystems are related to the batteries and the supercapacitors, evaluating whether they are capable of absorbing the energy from the braking. 
The calculation starts with the choice of the driving cycle, specified as an array of vehicle velocity versus time (at intervals of one second) [12]. This information is used to calculate the torque needed to operate the vehicle at each moment, considering aerodynamic drag, tire rolling resistance, climbing grade and vehicle inertia effects. The required total torque needed to drive the wheels at each moment is converted to power after calculating the speed of the motor (in rpm), taking into consideration the motor and the controller efficiencies. The time integral of power for the driving cycle gives the total needed energy or a specified route. Furthermore, the kinetic energy is calculated as a way of, after discounting the resistances' energy, finding out how much energy can be recovered from the regenerative braking. Then the batteries and supercapacitors were modeled to find out how much of the regenerative braking energy can be absorbed by them. The high-level scheme for this model structure can be observed in Figure 2.

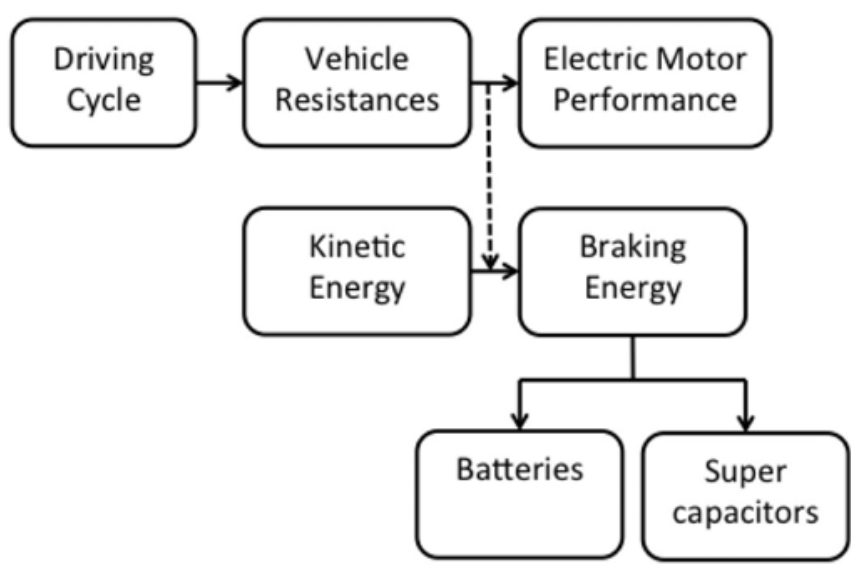

Figure 2. High-level model structure

\section{SYSTEM MODELING DESIGN}

\section{DRIVING CYCLE}

One critical component of the simulation is the driving cycle on which all the vehicle calculations are based [12]. For this study, a driving cycle was developed that simulates a stop-and-go part of a bus route. This part has a 10-second accelerating period, then 33 -second period of constant speed and a 7-second period of deceleration. The acceleration rates are based on the simulated performance of the bus considering the specifications of its electric motor and the gear ratios involved, respecting the speed limits for buses in urban areas of $50 \mathrm{~km} / \mathrm{h}$ [13]. The cycle corresponds to approximately 514 meters, which represents an average distance between bus stops in Europe [14]. This cycle can be observed in Figure 3.

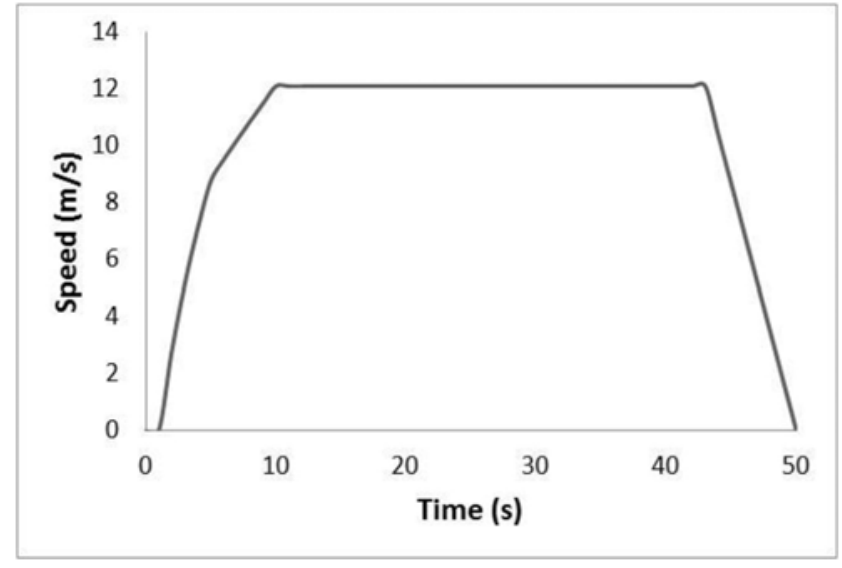

Figure 3. Driving cycle

\section{TRACTIVE FORCE}

This is the force propelling the vehicle forward, transmitted to the wheels. This force must overcome the vehicle resistance to the movement, which is composed by the sum of the different forces that act against its movement, such as the friction between the tires and the road (rolling resistance force), the resistance of air (aerodynamic drag force), the climbing grade (hill climbing force), and the inertia $[\underline{15}, \underline{16}]$.

\section{Rolling Resistance}

The rolling resistance force, $F_{r o}$, is primarily due to the friction of the vehicle tire on the road, but friction in bearings and on the gearing system must also be considered. The rolling resistance depends on vehicle speed and can be calculated by using an equation as a function of speed. The rolling resistance is also proportional to vehicle weight [12], [15], [16].

$$
F_{\text {ro }}=f . m \cdot g
$$

For the rolling resistance coefficient, the following expression was used [17]:

$$
f=(0.0041+0.000041 \cdot v \cdot 2.24) \cdot C_{h}
$$

Where:

$$
\begin{aligned}
& f=\text { rolling resistance coeficient } \\
& m=\text { mass of the vehicle }(\mathrm{kg}) \\
& g=\text { gravitational acceleration }\left(\mathrm{m} / \mathrm{s}^{2}\right) \\
& v=\text { linear speed }(\mathrm{m} / \mathrm{s}) \\
& C_{h}=\text { road surface coefficient }
\end{aligned}
$$




\section{Aerodynamic Drag}

The aerodynamic force $F_{l}$ is due to the friction of the vehicle body moving through the air. It depends on the frontal area, shape, protrusions (such as side mirrors), ducts and air passages, spoilers, and many other factors $[\underline{12}, \underline{15}$, 16].

$$
F_{l}=0.5 \cdot \xi \cdot C_{W} \cdot A \cdot\left(v^{2}\right)
$$

Where:

$$
\begin{aligned}
& \xi=\text { air density }\left(\mathrm{k} / \mathrm{m}^{3}\right) \\
& C_{W}=\text { aerodynamic drag coefficient } \\
& A=\text { vehicle frontal area }\left(\mathrm{m}^{2}\right) \\
& v=\text { vehicle speed }(\mathrm{m} / \mathrm{s})
\end{aligned}
$$

\section{Hill Climbing Force}

The hill climbing force $F_{s t}$ is the force needed to drive the vehicle up a slope. It is simply the component of the vehicle weight that acts along the slope. It may have a negative impact on the movement of the vehicle, acting indeed as a resistance force but also a positive impact, if the vehicle is going down a hill. In this case, this force helps the movement $[\underline{12}, \underline{15}, \underline{16}]$.

$$
F_{s t}=m \cdot g \cdot \sin \alpha
$$

Where:

$$
\alpha=\text { grade angle }
$$

\section{Acceleration Force}

A force has to be applied in addition to the forces already mentioned if the velocity of the vehicle is changing. The acceleration force $F_{t a}$ will provide the linear acceleration of the vehicle $[\underline{15}, \underline{16}]$.

$$
F_{t a}=m \cdot a
$$

Therefore, after the deduction and presentation of all the equations above, the total tractive force is their sum:

$$
F_{t e}=F_{r o}+F_{l}+F_{s t}+F_{t a}
$$

The torque can be expressed by $F_{t e} . r$, where $r$ is the radius of the tire, and $F_{t e}$ is the tractive effort delivered by the powertrain. Assuming $G$ as the gear ratio of the transmission system connecting the motor to the axle, and $T$ the motor torque $[\underline{16}]$ :

$$
T=\frac{F_{t e} \cdot r}{G}
$$

After calculating the tractive force, it is necessary to know the amount of power required for each instant of the driving cycle. This power can be calculated as a function of the vehicle torque and motor speed, according to the equation bellow. In order to know the amount of required energy to complete the driving cycle, one must make the integration of the power required for each instant [15].

$$
P=\frac{T \cdot v_{m} \cdot 2 \cdot \pi}{60000 \cdot \eta_{m} \cdot \eta_{c}}
$$

Where:

$$
\begin{aligned}
& P=\text { Power }(k W) \\
& T=\text { Torque }(N . m) \\
& v_{m}=\text { Motor speed }(r p m) \\
& \eta_{c}=\text { Controller efficiency } \\
& \eta_{m}=\text { Motor efficiency }
\end{aligned}
$$

The motor speed $v_{m}$ in revolutions per minute, can be calculated taking into account the linear speed, the perimeter of the wheel and the transmission gear ratio.

$$
v_{m}=\frac{v \cdot 60 . G}{2 \cdot \pi \cdot r}
$$

\section{KINETIC ENERGY}

The effect of the vehicle mass when accelerating and stopping in town and city conditions is another area where the mass of the electric vehicle will have considerable influence on vehicle performance [16]. Basically when a vehicle of mass $m$ (in $\mathrm{kg}$ ) is travelling at velocity $v$ (in $\mathrm{m} / \mathrm{s}$ ) its kinetic energy is given by:

$$
E_{k}=\frac{1}{2} \cdot m \cdot v^{2}
$$

If the vehicle brakes, this kinetic energy is converted into heat at the braking disks. When regenerative braking is used a certain amount of the energy is recovered. The kinetic energy is being used in this model for calculating the amount of energy dissipated in braking, considering the tires and air resistance and the climbing grade, which can contribute positively or negatively to the regenerative braking. 


\section{VARIABLES DEFINITON AND RESULTS}

The data used hereafter is taken from an actual CaetanoBus electric bus, currently under its testing phase in Portugal. This electric bus has a brushless permanent magnetic motor, with a 650 N.m peak torque, $150 \mathrm{~kW}$ peak power also capable of working as a generator to allow regenerative braking. Motor efficiency data was extracted from the supplier's plot of motor efficiency versus motor speed (Appendix 1) and that can be represented by the following equation:

$$
\eta_{m}=-3 \cdot\left(10^{-8}\right) \cdot\left(v_{m}^{2}\right)+0.0002 \cdot v_{m}+0.638
$$

Table 1 shows the necessary parameters used to calculate the tractive force:

Table 1. Variables Definition

\begin{tabular}{|l|l|}
\hline Tire Radius $(r)$ & $0.5 \mathrm{~m}$ \\
\hline Road Surface Coefficient $\left(C_{h}\right)$ & 1.2 \\
\hline Vehicle Frontal Area $(A)$ & $10 \mathrm{~m}^{2}$ \\
\hline Gravitational Acceleration $(g)$ & $9.8 \mathrm{~m} / \mathrm{s}^{2}$ \\
\hline Climbing Grade & $0^{\circ}$ (ground level) \\
\hline Aerodynamic Drag Coefficient $\left(C_{w}\right)$ & 1.17 \\
\hline Air Density $(\xi)$ & $1.2 \mathrm{~kg} / \mathrm{m}^{3}$ \\
\hline Vehicle Mass $(m)$ & $17,048 \mathrm{~kg}$ \\
\hline Controller Efficiency $\left(\eta_{c}\right)$ & $92 \%$ \\
\hline & $\begin{array}{l}\text { First Gear: } 1: 3 \\
\text { Second Gear: } 1: 1 \\
\text { Differential: } 8.83\end{array}$ \\
\hline
\end{tabular}

By using the equations presented above, it was possible to calculate the torque for each step of the driving cycle, as it can be observed in Figure 4. With these torque and motor speed, the power for each second of the driving cycle was also calculated as shown in Figure 5 .

During these simulations it was also calculated the several energy consumers occurring during the electric bus operation. These consumers of energy comprehend aerodynamic drag, rolling resistance, the bus inertia and inefficiencies that are associated with the performance of several bus components, mainly of the powertrain, namely the motor and the controller. In the plot presented in Figure 6 it can be seen the importance of each of these factors on the overall energy consumption of the proposed cycle. As it can be seen only $45 \%$ of the total energy used to power the bus has potential to be recovered on a regenerative braking.

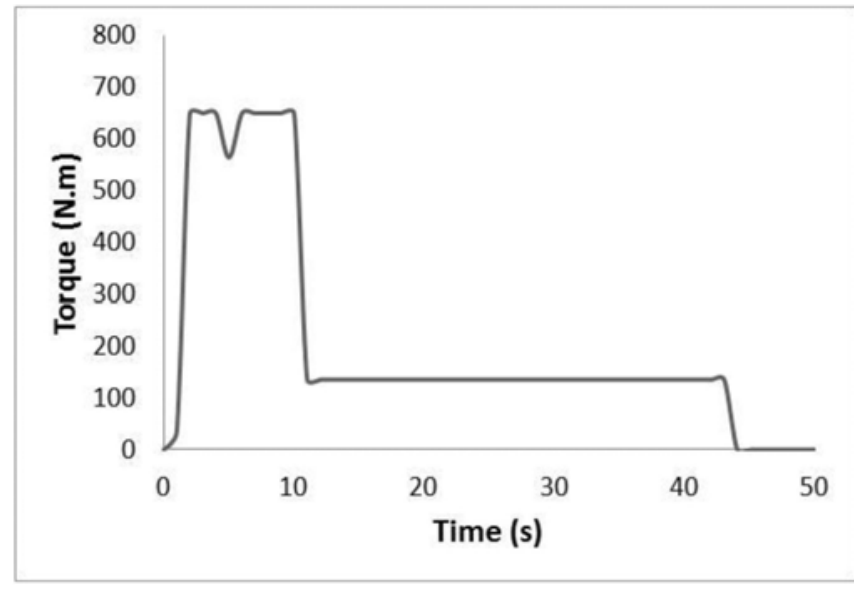

Figure 4. Torque demand versus time

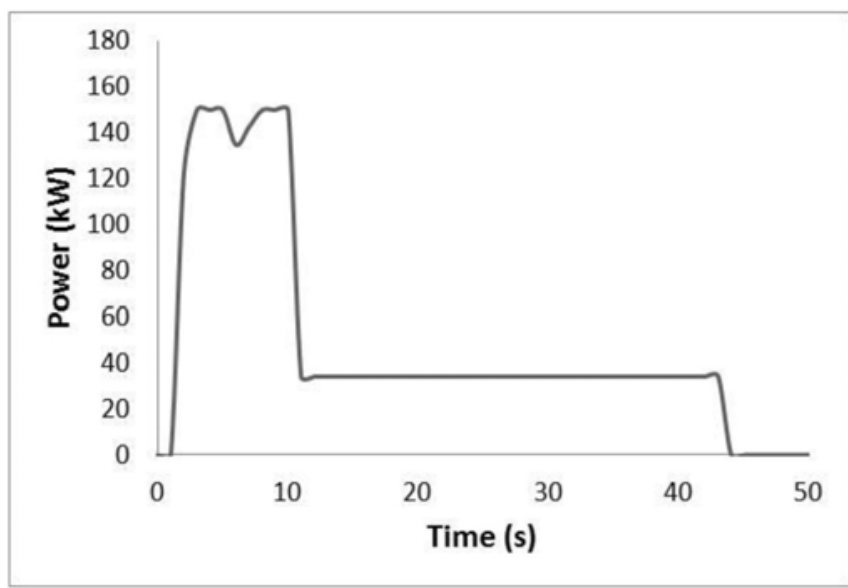

Figure 5. Power demand versus time

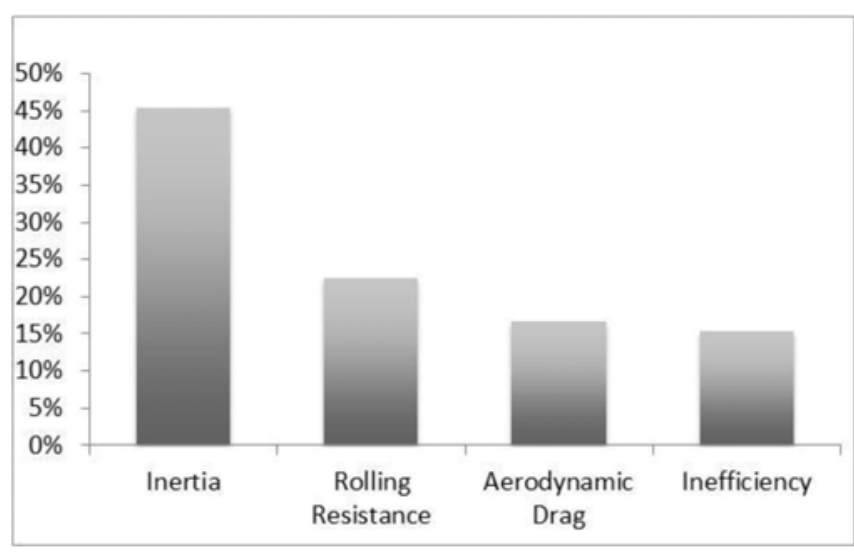

Figure 6. Energy Distribution

The next step was to find how much energy is dissipated while braking. To allow this, the first thing that was done was to calculate the kinetic energy for the point where the bus starts to decelerate (at 44 seconds), as this value represents 
the amount of energy the bus has in that moment and will be dissipated until it stops. From this value, it was subtracted the energy necessary for overcoming the resistances' forces during the braking. The power to overcome these forces was calculated for each simulation step of the cycle. Afterwards, a subroutine was created as a way of limiting the collection of these data during negative acceleration, meaning that the vehicle is slowing down and/or braking and the motor enters generator mode allowing for regenerative braking. Then, it was performed the integration of this power in order to find the energy required for overcoming these resistances in this period of time. The graph showing the kinetic energy and the resistances energy versus time during the braking period is presented in Figure 7.

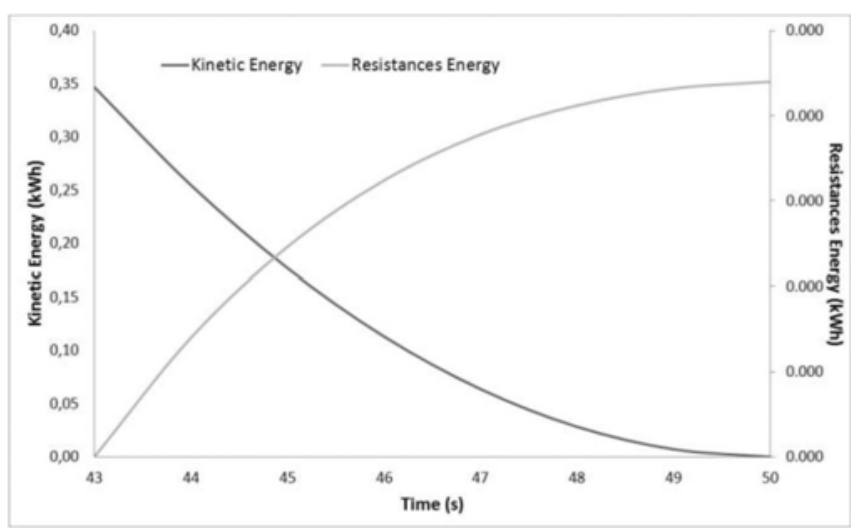

Figure 7. Kinetic Energy and Resistances Energy during braking versus time

Therefore, the kinetic energy at instant 44 seconds is 347 Wh and the energy required for overcoming the resistances during the braking period is $22 \mathrm{Wh}$. Thus, the amount of energy available for being recovered while braking is 325 Wh, which compared to the amount of energy required for completing the cycle $(656 \mathrm{Wh})$, represents almost $50 \%$. It should be considered the efficiency of the motor when working as a generator, as it plays a main role in this energy recovery process and in this case, it is being considered the worst case scenario from the supplier's plot (Appendix 2), which is $65 \%$ and applied to the braking energy of $325 \mathrm{Wh}$, it gives $210 \mathrm{Wh}$ ( $32 \%$ of the total energy of the cycle). Certainly the recovery of this energy is mainly dependent on the ability of the energy storage system of absorbing it, and this will be discussed hereafter.

The next step was to analyze how much of the energy dissipated in braking can be absorbed by lithium-ion batteries. The battery selected for analysis was taken from the same CaetanoBus electric bus model as referred above. The most relevant battery data is presented in Table 2 .
Table 2. Battery data

\begin{tabular}{|l|l|}
\hline Type of Battery & $\mathrm{LiFePO} 4$ \\
\hline Nominal Capacity & $3 \mathrm{Ah}$ \\
\hline Maximum Charging Current & $1 \mathrm{CA}$ \\
\hline Maximum Charging Voltage & $3.65 \mathrm{~V}$ \\
\hline Number of Cells in Parallel & 140 \\
\hline Number of Cells in Series & 112 \\
\hline Weight & $90 \mathrm{~g}$ \\
\hline Total battery pack weight & $1,411 \mathrm{~kg}$ \\
\hline Total battery pack storage capacity & $172 \mathrm{kWh}$ \\
\hline
\end{tabular}

One of the main assessments to be performed is whether the lithium-ion batteries are able to absorb the burst of energy that a braking can cause. Usually, this energy is converted into heat and dissipated through the brake system. Therefore, the question is how much allowance does the battery system gives for taking some of the work from the common braking system into the motor/generator and therefore recovering it back to the system and into the batteries.

Table 2 shows that there are both batteries in series and in parallel. In this case, there are 112 cells in series with a maximum charging voltage of $3.65 \mathrm{~V}$ each, which gives a maximum voltage of $408.8 \mathrm{~V}$ for the system. Analogously, batteries in parallels have their current capability multiplied by the number of cells in parallel. For this specific case the maximum charging current is $1 \mathrm{CA}-1$ times the nominal capacity of the cell, 3 Ah- totaling 420 A of maximum current capability for the entire battery system.

However, due to charging characteristics of these batteries the controller limits the current transfer due to an increase on voltage -necessary to properly charge such systems. In this particular case, the amount of regenerative braking current allowed by the controller is $200 \mathrm{~A}$, value used for the following calculations.

By using the battery block from Simulink, and applying all the parameters of this block taking into consideration the amount of batteries in parallel and in series that the system has, the charging of the batteries for seven seconds (braking episode duration) was simulated, assuming a initial state of charge (SOC) of $50 \%$ and a constant current of $200 \mathrm{~A}$ (maximum allowed current for the regenerative braking). The outcome of this model is the evolution of the SOC and the voltage. By applying equation 12 , one must find the amount of energy (in kWh) that the batteries were able to absorb in this period of time [16].

$$
E_{b}=\left(\int_{0}^{7}(i . V)\right) \cdot 3 \cdot 6 \cdot 10^{-6}
$$


Table 3. Supercapacitor Data

\begin{tabular}{|l|l|}
\hline Type of Capacitor & Supercapacitors Module \\
\hline Rated Capacitance & $63 \mathrm{~F}$ \\
\hline Rated Voltage & $128 \mathrm{~V}$ \\
\hline Resistance & $18 \mu \Omega$ \\
\hline Maximum Continuous Current $\left(940^{\circ} \mathrm{C}\right)$ & $240 \mathrm{~A}$ \\
\hline Peak Current, during 1 second & $1,900 \mathrm{~A}$ \\
\hline Weight & $60.5 \mathrm{~kg}$ \\
\hline
\end{tabular}

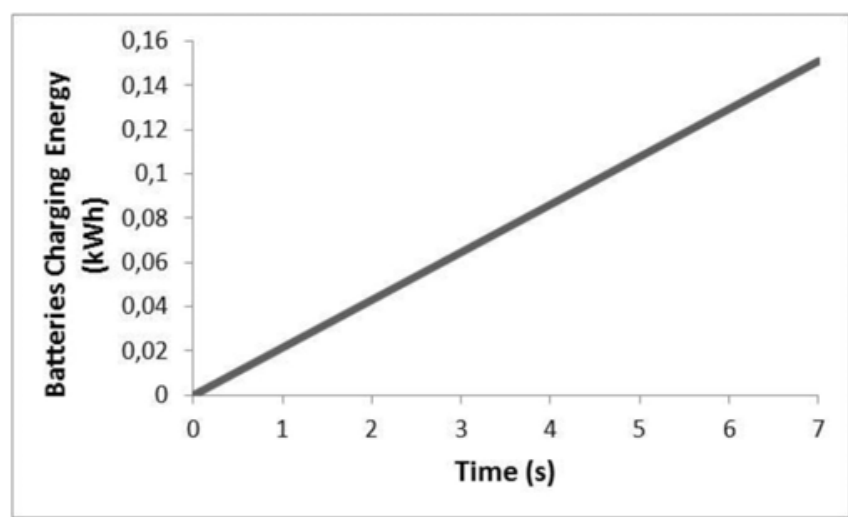

Figure 8. Batteries absorbed energy versus time

From the graph of Figure 8 , it can be noticed that the amount of energy that the system of batteries can stand during the recovery process, submitted to a constant current of $200 \mathrm{~A}$, is $0.15 \mathrm{kWh}$. This value represents $68 \%$ of the amount of energy that is dissipated while braking, which can be considered a significant value. However, it is important to state that in a real system, this value would be lower, as the batteries efficiency should be considered.

On the other hand, it is necessary to calculate the amount of energy that a supercapacitor is able of absorbing in the same braking episode ( 7 seconds). It is expected a higher value, once they have a much higher power density when compared to batteries. The chosen model to be analyzed was from Maxwell Technologies [18], model BMOD0063 PI25 $B 03$, since this model is specific for heavy-duty vehicle application. Some important data of this supercapacitor is presented in Table 3.

For this study case, it was considered the use of two modules in series. Therefore, the total rated voltage would be $256 \mathrm{~V}$ and $31.5 \mathrm{~F}$ of capacitance. In order to know how much energy this system of supercapacitors can absorb, the first step is to calculate the amount of electric charge (C) it absorbs in time [19]:

$$
Q=C \cdot V \cdot\left(1-e^{-t / R C}\right)
$$

Where:

$$
\begin{aligned}
& C=\text { capacitance }(F) \\
& V=\text { voltage }(V) \\
& R C=\text { time constant }
\end{aligned}
$$

The time constant is expressed by the multiplication of resistance (in $\Omega$-ohm) and capacitance (in F- farad). The next step is to calculate the energy (in $\mathrm{kJ}$ ) from the information of electric charge, using equation 14. The graph presenting the energy versus time that these supercapacitors can absorb is showed in Figure 9.

$$
E=\frac{1}{2000} \cdot \frac{Q^{2}}{C}
$$

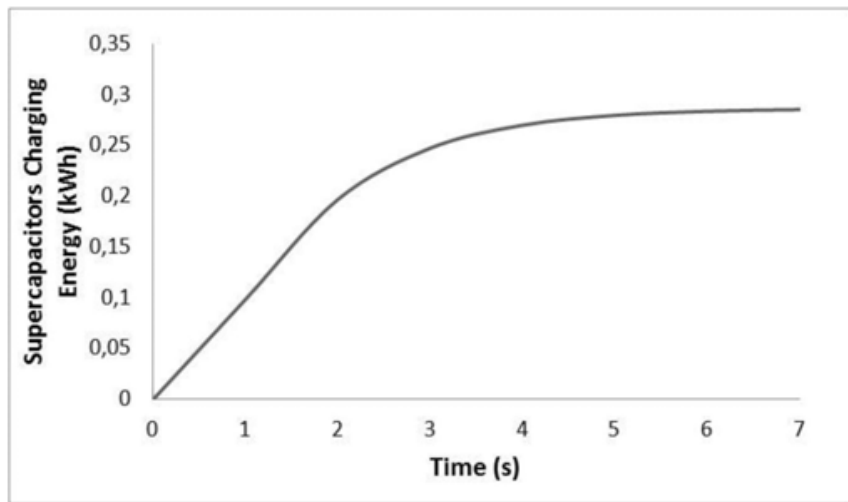

Figure 9. Supercapacitors absorbed energy versus time

As it can be noticed, the supercapacitors can absorb a high amount of energy in a small period of time. After this period (7 seconds), they are practically fully charged (it can be noticed by the linear region of the graph). Thus, in seven seconds, they are able of absorbing $280 \mathrm{Wh}$ of energy, which compared to the value of $210 \mathrm{Wh}$ of regenerative braking energy potential, makes them suitable for this application. This implies that the supercapacitors have a better 
performance than the batteries concerning the regenerative braking energy absorption.

It is important to point out that this ability is not only applied for charging, but also for discharging, which means that those supercapacitors could be used for the initial phase of acceleration. Being this regenerative braking energy amount significant (representing 32\% of the total energy supplied during the cycle), it is plausible to think that, being the electric system able of recovering all this amount when using supercapacitors, the battery pack can be now considered over-dimensioned, and it should be analyzed how much weight can be saved in batteries (assuming the addition of two modules of supercapacitors, totalizing $121 \mathrm{~kg}$ ).

In order to know how much the charged supercapacitors, after the braking period, can contribute by providing energy to the initial acceleration, one must know their discharging curve, which can be plotted based on the equation bellow and further apply equation 14 [19]. The discharging curve for the system of supercapacitors is in Figure 10.

$$
Q=C \cdot V \cdot\left(e^{-t / R C}\right)
$$

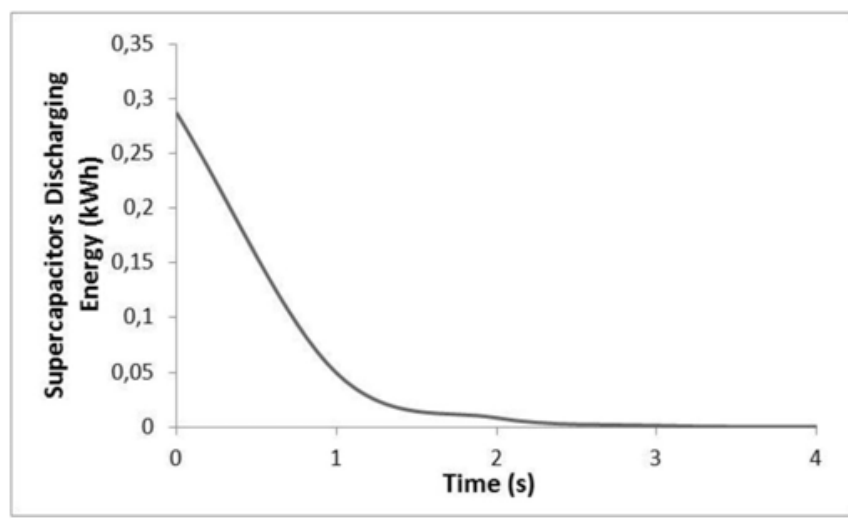

Figure 10. Supercapacitors discharging energy versus time

According to Figure 10, the supercapacitors can discharge in a very high rate (they are almost fully discharged in four seconds, with a discharge peak in the first second). For this reason, when compared to batteries, they can be easily considered a much better solution to store the energy from braking and to further use this energy for acceleration. However, in a system where there are supercapacitors and batteries working together, there should be done a correct management of the energy flow from and to the motor. Thus a DC-DC converter should be used [20], and the powertrain structure could be based on the example presented in Figure 11. In absence of the DC-DC converter, with the supercapacitors and batteries directly connected in parallel, it would be impossible to control the energy flow between the supercapacitors and the traction system, since it would depend only on the voltage and on the internal resistance values. With a current-controlled DC-DC converter, and based on the power required by the drive train and on the state of charge of the supercapacitors, it is possible to regulate the power rate from and to the supercapacitors according to a defined strategy [21]. There are some studies in the literature that analyses the architecture of hybrid storage systems (with batteries and supercapacitors) and/or the management of energy flow related to regenerative braking; some focusing on supercapacitors behavior modeling and energy management strategy [22], others on the modeling and control aspects of regenerative controlled electric drive systems using supercapacitors as energy storage element and as emergency power supply device [23].

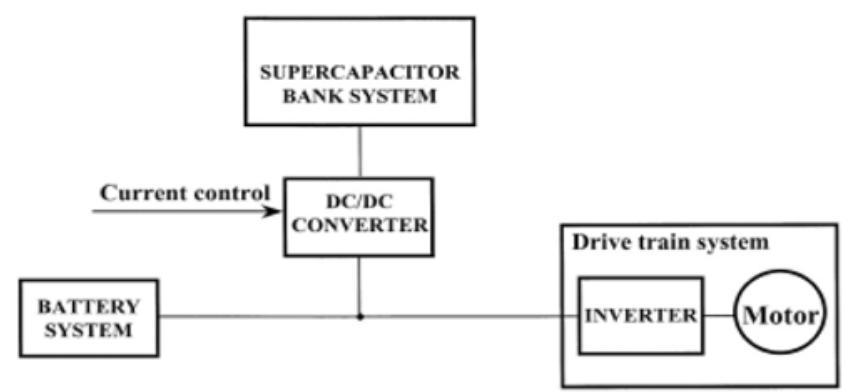

Figure 11. Power train structure with DC-DC converter and supercapacitors series connected Source: $E$. Faggioli et. all [21]

In order to have a clearer picture of the amount of energy involved, the analysis will be held for a whole bus route. From the website of a transportation company in Portugal [24], it was taken as an example a bus route with forty stops (correspondent to eighty cycles, considering return trip). To gain some insight, it was assumed the same performance for each of the stops (same acceleration and deceleration rates and periods). Usually, a bus makes two return trips per shift, stopping between shifts for refueling. With electric buses, this stop between shifts is for the battery recharge or exchange of the battery pack by one that is already charged in a central station. Assuming that the electric bus makes two complete route cycles, the total amount of energy that this bus needs for completing the shift is $104.96 \mathrm{kWh}$.

Considering that the supercapacitors will contribute with all the energy absorbed while braking, which corresponds to $32 \%$ of the total amount of energy of the cycle, it is plausible to say that the battery pack will now need to provide only $68 \%$ of the energy of the cycle, corresponding to $71.37 \mathrm{kWh}$. However, the state of charge of the battery cannot fall below $20 \%$ and thus this margin was considered, which gives 85.64 $\mathrm{kWh}$ in batteries, correspondent to $50 \%$ of the original battery pack. Thus the battery pack can suffer a reduction of $50 \%$, weighing now $705.6 \mathrm{~kg}$. Therefore, the total weight in energy storage devices that the bus would carry would be $826.6 \mathrm{~kg}$ (by adding $121 \mathrm{~kg}$ in supercapacitors). Figure 12 shows that initially the amount of weight carried in batteries represented $8 \%$ of the total weight of the bus, considering that the bus is 
driven with full passenger capacity. After the reduction of the battery pack and the addition of the supercapacitors banks, this value dropped to $5 \%$.

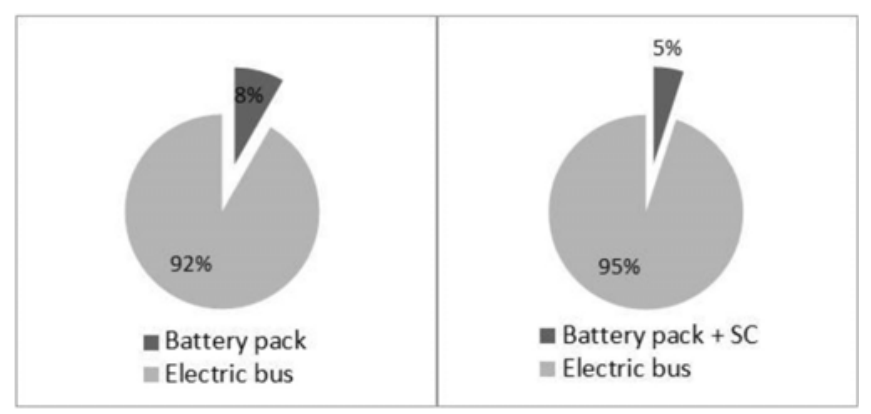

\section{Figure 12. Ratio of weight in energy storage devices before (left) and after (right) optimization}

After running the simulation program with the new value of vehicle weight, the total energy for completing the cycle is now $104 \mathrm{kWh}$ against $104.96 \mathrm{kWh}$ with the original weight, representing a $0.9 \%$ reduction in energy consumption. In relative values, it may seem a small gain, but by analyzing the absolute value, the gain is $0.96 \mathrm{kWh}$. This amount of energy represents the necessary energy to complete almost 1.5 cycles.

The results accomplished so far are preliminary, once there are other factors that were not considered for this analysis related with the bus energy consumption such as air conditioning/ heating of the bus cabin, either heating or cooling, opening and closing doors, light signs, and other factors such as traffic, efficiency from batteries among others. The considered weight of the bus assumed a full capacity of passengers, though in a regular trip, there are variations in the number of passengers carried, which will lead to higher energy saving results, once in this analysis the maximum bus weight was considered.

\section{CONCLUSIONS}

It was analyzed the ability of lithium-ion batteries and supercapacitors of absorbing bursts of energy originated in electric bus braking. In this specific case, an electric bus is subjected to constant stops, and it has a mass of $17,048 \mathrm{~kg}$, increasing its kinetic energy. It could be confirmed through the simulation program that supercapacitors are able of absorbing much more power than the batteries in a short period of time, as expected. Batteries are great in energy density; they can store much more energy when compared to supercapacitors. However, they need longer periods of time to make an appropriate charge and increase their life cycle. On the other hand, supercapacitors can store much less energy but they are able of being charged much faster and it does not put at risk their life cycle.

By replacing part of the batteries by supercapacitors in order to increase performance on regenerative braking, the weight of the bus falls down about $5 \%$, considering the bus empty. The simulation program was used again to simulate the gain in energy that the bus would have. The amount of energy required in both situations was extrapolated for a whole bus route cycle, composed of forty stops and considering return trip, totalizing 80 stops. The final values indicate a gain of $0.9 \%$, represented by $960 \mathrm{Wh}$ of saving, correspondent to about 1.5 cycles. It is important to mention that all calculations were held taking into consideration the most critical scenario: the bus is circulating with full capacity of passengers. If one considers an empty bus or a bus with passengers quantity variation, this value of energy saving will be higher. These results will serve as an initial step for the study of the use of batteries in conjunction with supercapacitors, trying to find the ideal ratio of the number of batteries and supercapacitors in order to improve the electric bus performance.

\section{REFERENCES}

1. Gee, G. C. and Takeuchi, D. T., "Traffic stress, vehicular burden and well-being: a multilevel analysis.," Social science \& medicine (1982), vol. 59, no. 2, pp. 405-414, Jul. 2004

2. Gakenheimer, R., "Urban mobility in the developing world," Transportation Research Part A: Policy and Practice, vol. 33, no. 7-8, pp. 671-689, Nov. 1999

3. "Eurostat - Motorisation Rate." [Online]. Available: http:// epp.eurostat.ec.europa.eu/tgm/table.do? $\underline{\text { tab }}=$ table\&init $=1$ \&plugin $=1$ \&language $=$ en $\&$ pcode $=$ tsdpc 340 [Accessed: 08-Sep-2011].

4. Unger, N. et al., "Attribution of climate forcing to economic sectors," Proceedings of the National Academy of Sciences of the United States of America, vol. 107, no. 8, pp. 3382-7, Feb. 2010.

5. Pope, C. A., Ezzati, M., and Dockery, D. W., "Fine-particulate air pollution and life expectancy in the United States.," The New England journal of medicine, vol. 360, no. 4, pp. 376-86, Jan. 2009.

6. Advantages, E. B., "Electric Buses : Green Public Transport or THE Public Transport?," Enviro: News and Business, p. 2, 2009.

7. Sinautec," "Sinautec Automobile Technologies L.L.C." [Online]. Available: http://www.sinautecus.com/index.html.

8. Altairnano," "Altairnano." [Online]. Available: http:// www.altairnano.com/. [Accessed: 29-Mar-2011].

9. Proterra," "Proterra." [Online]. Available: http://www.proterra.com index.php. [Accessed: 31-Mar-2011].

10. Cikanek, S. R. and Bailey, K. E., "Regenerative braking system for a hybrid electric vehicle," Proceedings of the 2002 American Control Conference (IEEE Cat. No. CH37301), pp. 3129-3134, 2002.

11. Chu, A. and Braatz, P., "Comparison of commercial supercapacitors and high-power lithium-ion batteries for power-assist applications in hybrid electric vehicles I. Initial characterization," Journal of Power Sources, vol. 112 , no. 1 , pp. $236-246$, Oct. 2002.

12. Malcolm, E. M. D. Weiss, A., Heywood, John B. and Schafer, F. F. A. Andreas, "ON THE ROAD IN 2020 - A life-cycle analysis of new automobile technologies," 2000

13. E. C. of M. of T. (ECMT) Organisation for Economic Co-operation and Development (OECD), "Speed Management," 2009

14. E. S. C. and A. G. N. Homero F. Oliveira, Gonçalves, Mirian B. "Development of a Computational System to Determine the Optimal Bus-stop Spacing in order to Minimize the Travel Time of All Passengers," in Logistics Dynamics - Second International Conference, 2009.

15. Ehsani, M., Rahman, K. M., and Toliyat, H. a., "Propulsion system design of electric and hybrid vehicles," IEEE Transactions on Industrial Electronics, vol. 44, no. 1, pp. 19-27, 1997.

16. Larminie, J. and Lowry, J., Electric Vehicle Technology Explained. John Wiley \& Sons Ltd, 2003, pp. 62; 183-186.

17. Gillespie, T., "Fundamentals of Vehicle Dynamics," SAE International, Warrendale, PA, ISBN 978-1-56091-199-9, 1992. doi:10.4271/R-114.

18. "Maxwell Technologies." [Online]. Available: http:// www.maxwell.com. [Accessed: 20-Sep-2011].

19. Conway, Brian E., Electrochemical supercapacitors: scientific fundamentals and technological applications, 1st ed. Springer, 1999, p. 736.

20. Arnet, B. J. and Haines, L. P., "High power DC-to-DC converter for supercapacitors," IEMDC 2001. IEEE International Electric Machines and Drives Conference (Cat. No.01EX485), pp. 985-990, 2001. 
21. Faggioli, E., Rena, P., Danel, V., Andrieu, X., Mallant, R., and Kahlen, H., "Supercapacitors for the energy management of electric vehicles," Journal of Power Sources, vol. 84, no. 2, pp. 261-269, Dec. 1999.

22. Camara, M. B., Gualous, H., Gustin, F., Berthon, A., and Dakyo, B., "DC / DC Converter Design for Supercapacitor and Battery Power Management in Hybrid Vehicle Applications - Polynomial Control Strategy," vol. 57, no. 2, pp. 587-597, 2010.

23. Grbovi, P. J., Member, S., Delarue, P., Le, P., and Member, M., "Modelling and Control of the Ultra-Capacitor Based Regenerative Controlled Electric Drives," 2010.

24. "STCP - Sociedade de Transportes Colectivos do Porto, SA." [Online]. Available: http://www.stcp.pt. [Accessed: 25-Sep-2011].

\section{CONTACTS}

\section{Author}

Deborah Perrotta de Andrade

PhD Researcher at MIT Portugal Program

Contact:(+351) 934753738

deborahperrotta@gmail.com

\section{ACKNOWLEDGMENTS}

This work is financed by FEDER Funds, through the Operational Programme for Competitiveness Factors COMPETE under the project 13844. Deborah Perrotta thanks FCT (Fundação para a Ciência e Tecnologia) for $\mathrm{PhD}$ scholarship (SFRH / BD / 51256 / 2010) under the scope of the MIT Portugal Program in Engineering Design and Advanced Manufacturing - Leaders for Technical Industries focus area. 


\section{APPENDIX}

\section{APPENDIX 1 - MOTOR EFFICIENCY IN MOTORING MODE}

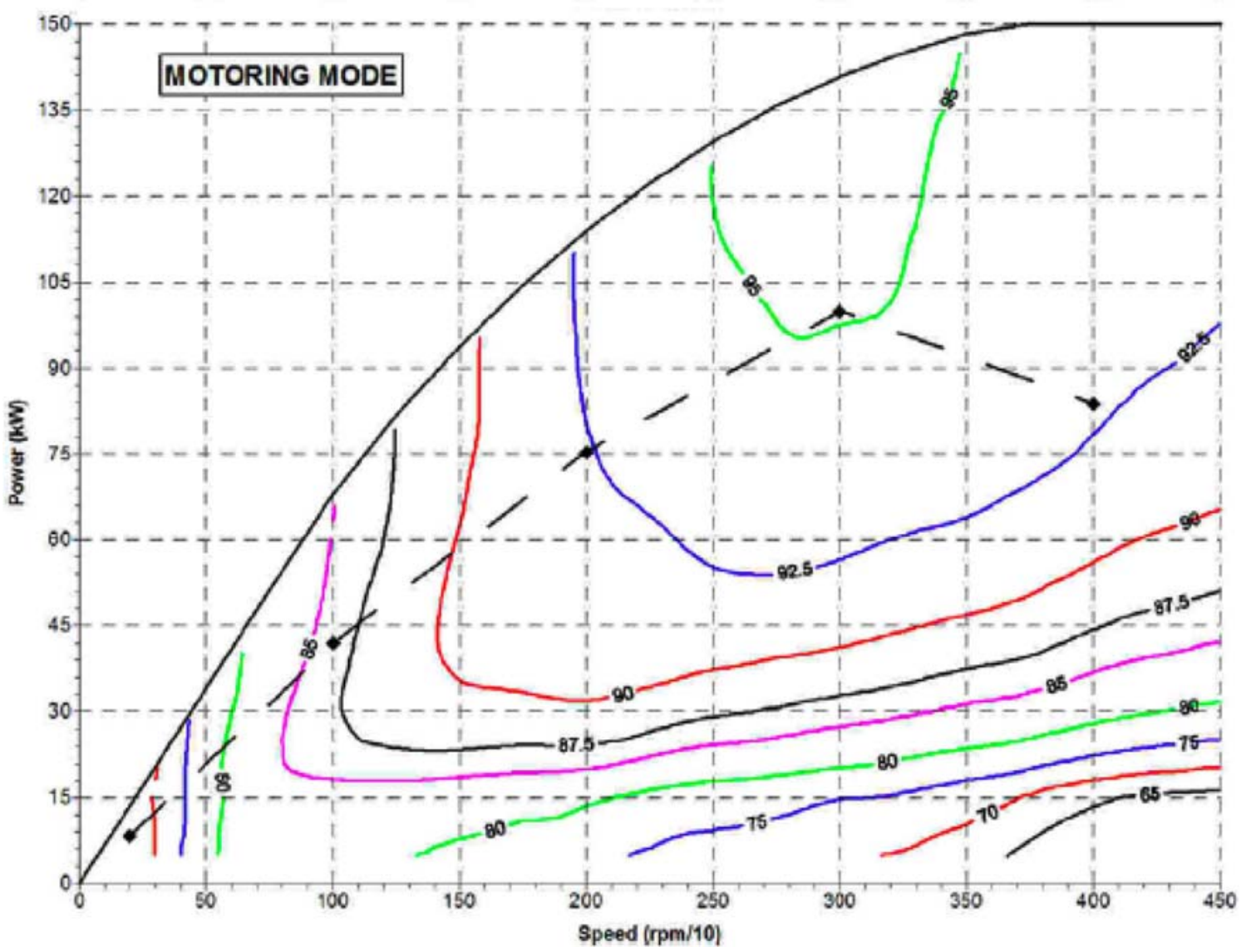




\section{APPENDIX 2 - MOTOR EFFICIENCY IN GENERATOR MODE}

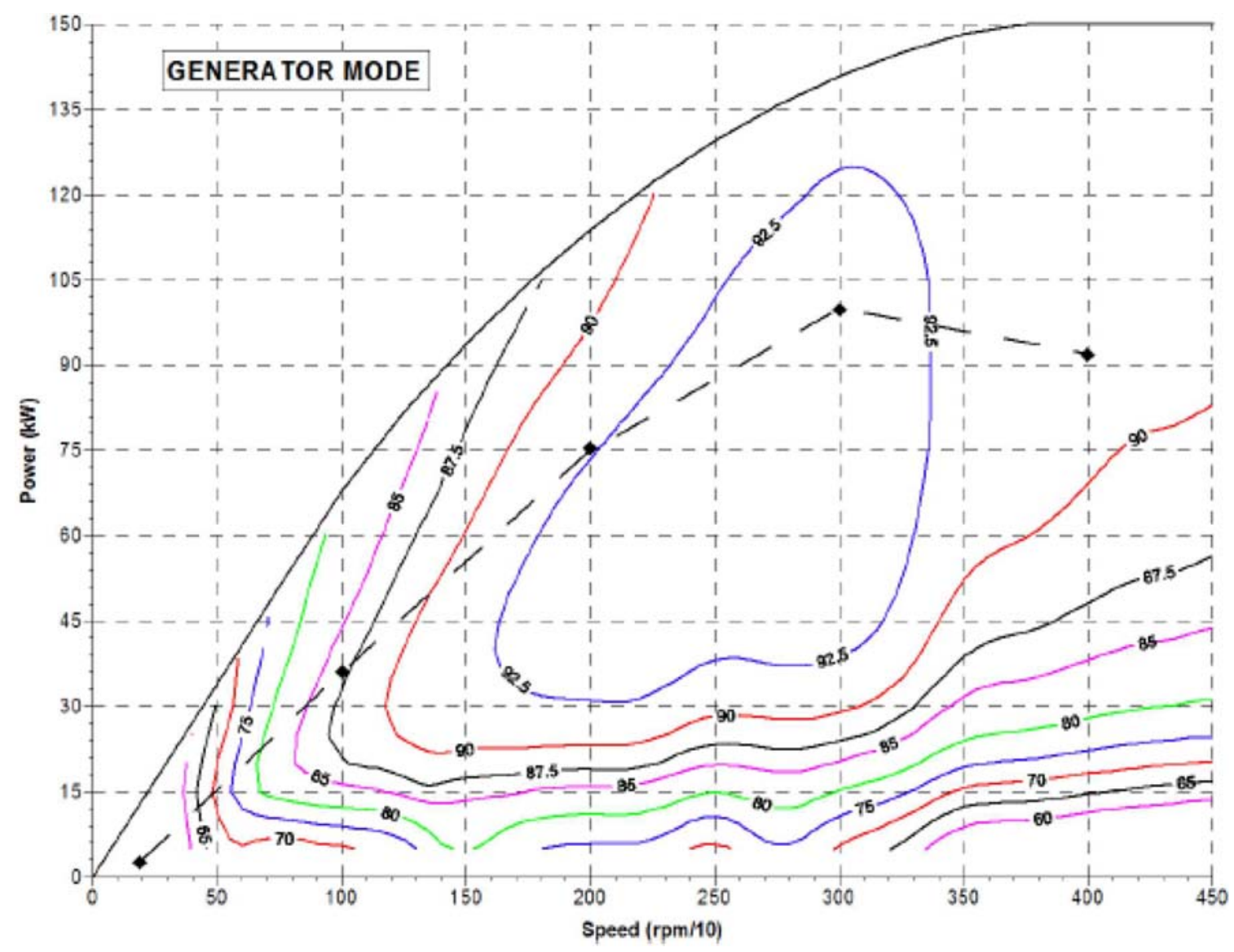

